Localizador: 18058

doi: $10.35366 / 91755$

\title{
Mucina1 (MUC1) en los engrosamientos epidérmicos del carcinoma basocelular (CBC)
}

\author{
Mucin1 (MUC1) in the epidermal thickening of the basal cell carcinoma (BCC)
}

Adriana De la Torre, ${ }^{*}$ Luz Marina Carrillo, ${ }^{*}$ Enrique Arciniegas, ${ }^{\ddagger}$ Héctor Rojas, ${ }^{\S}$ Oscar Reyes*

Palabras clave: Mucina1, carcinoma

basocelular,

engrosamientos epidérmicos, NFkB.

Keywords: Mucin1, basal cell carcinoma, epidermal thickening, $N F_{\kappa} B$.

* Servicio Autónomo Instituto de Biomedicina. * Instituto de Biomedicina.

$\S$ Instituto de Inmunología.

Universidad Central de Venezuela. Caracas. República Bolivariana de Venezuela.

Conflicto de intereses: Ninguno.

Recibido:

10/Septiembre/2018

Aceptado:

08/Octubre/2018

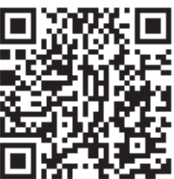

\section{RESUMEN}

Introducción: Mucina1 (MUC1) es una glicoproteína transmembrana normalmente expresada en la cara apical de muchas células epiteliales secretoras. MUC1 es sobreexpresada en diversos carcinomas, siendo considerada como sensor molecular y transductor de señales en respuestas a estímulos externos. Sin embargo, el significado de esta sobreexpresión en células tumorales, así como su papel en $\mathrm{CBC}$, aún no han sido determinados. Objetivos: Investigar por métodos inmunohistoquímicos si MUC1 está presente en los engrosamientos epidérmicos observados en CBC superficial. Examinar la presencia y localización de NFkBp65, NFкBp50, c-Src, ECFR y ErbB2 en sus formas activadas en algunas de esas biopsias. Metodología: Ocho biopsias de pacientes diagnosticados con CBC superficial fueron seleccionadas. Seis muestras de piel normal también fueron examinadas. La presencia y distribución de esas proteínas fue evaluada por inmunofluorescencia con un microscopio confocal. Resultados: La inmunotinción reveló que MUC1 estaba presente en los engrosamientos epidérmicos de todas las biopsias examinadas. También demostró que las formas activadas de NFkBp65, NFkBp50, IKK $\alpha / \beta$ y c-Src estaban presentes en los engrosamientos donde MUC1 fue detectada. Adicionalmente, mostramos que las formas activadas de EGFR y ErbB2 estaban localizadas en el núcleo de muchas de las células. Conclusiones: Basados en nuestras observaciones y estudios previos, proponemos que la estimulación de los queratinocitos (por exposición a las radiaciones UV, daño mecánico, factores de crecimiento o citocinas) podría activar a aquellas moléculas como c-Src e IKKa que favorecen la translocación de NFkB y la eventual expresión de MUC1. Una vez expresada, MUC1 estaría participando en algunas respuestas celulares como la proliferación, pérdida de las uniones intercelulares, migración y supervivencia de los queratinocitos.

\section{ABSTRACT}

Introduction: Mucin1 (MUC1) is a transmembrane glycoprotein normally expressed on the apical side of many secretory epithelial cells. It is overexpressed in many carcinomas being considered as molecular sensor and signal transducer in response to external stimuli. However, its possible role in $C B C$ has not been considered. Aim: To ascertain whether MUC1 is present in the epidermal thickening of $C B C$ superficial. Also, to examine the presence and location of NFkBp65, NFkBp50, c-Src, EGFR and ErbB2 in their activated forms in some of these biopsies. Methodology: Eight biopsies of patients diagnosed with superficial BCC were selected. Six samples of normal skin were also examined. The presence of these proteins was assessed by immunofluorescence with a confocal microscope. Results: Immunostaining revealed that MUC1 was present in the epidermal thickening of all biopsies examined. Also, demonstrated that the activated forms of NFkBp65, NFkBp50, $I K K \alpha / \beta$, and $c-S r c$ were present in these thickened where MUC1 was detected. Additionally, we show that the activated forms of EGFR and ErbB2 were located in the nucleus of many of the thickened epidermal cells. Conclusions: Based on our observations and previous studies, we propose that the stimulation of keratinocytes (by exposure to UV radiation, mechanical damage, growth factors or cytokines) may enable those molecules such as C-Src and IKKa favoring the activation of NFk $\beta$ and the eventual expression of MUC1. Once expressed MUC1 would be participating in some cellular responses such as cell proliferation, loss of intercellular junctions, migration and survival of keratinocytes.
$\mathrm{E}^{\prime}$ I carcinoma basocelular (CBC) es un tumor por una hiperplasia epidérmica, la cual involucra hiperproliferación, migración, expansión, invasión y supervivencia de los queratinocitos.
Existen factores predisponentes para el desarrollo y la progresión de este carcinoma, siendo la exposición prolongada a las radiaciones ultravioletas (RUV) provenientes de la luz solar el factor más importante. ${ }^{1,2}$ A este respecto, estudios in vivo e in vitro han mostrado que la exposición a RUV induce la proliferación de los queratinocitos y la hiperplasia epidérmica 
a través de la activación de receptores tirosinas quinasas (RTKs) tales como el EGFR y TNFR1, así como de la activación de rutas de señalización mediadas por la tirosina quinasa c-Src. ${ }^{3-5}$ De acuerdo con estos estudios, EGFR es el RTK más expresado por los queratinocitos basales y en menor grado por los suprabasales. Este RTK participa en la proliferación de los queratinocitos basales y retarda la apoptosis de los suprabasales que han perdido su interacción con la matriz extracelular. Es importante señalar que la activación de EGFR ha sido implicada en la renovación de la epidermis, regeneración después de un daño, modulación de la respuesta inmune y en la carcinogénesis. ${ }^{3,4}$ Los mismos estudios sugieren que muchas de estas respuestas son debidas a la activación de factores de transcripción nuclear tales como el factor de transcripción nuclear kB $(\mathrm{NF} \kappa \mathrm{B})$, el cual regula la expresión de un número importante de genes. ${ }^{3,5}$

Mucina1 (MUC1), también conocida como DF 3, CA15-3, EMA o episialina, es una glicoproteína transmembrana normalmente expresada sobre la superficie apical de las células epiteliales del tracto respiratorio y tracto gastrointestinal, así como en las células epiteliales de los ductos de varios órganos que incluyen a la glándula mamaria, pulmón, hígado, páncreas y glándulas sebáceas, ecrinas y apocrinas de la piel. ${ }^{6-10} \mathrm{Al}$ parecer, MUC1 es sobreexpresada en diversos tipos de carcinomas y en ciertas malignidades hematológicas, ${ }^{6-14}$ siendo considerada como un sensor molecular y transductor de señales en respuestas a estímulos externos que dan lugar a la respuesta inmune y a ciertos eventos celulares, que incluyen la interacción célula-célula, adhesión, proliferación, diferenciación, migración, invasión, supervivencia y secreción de factores de crecimiento y citocinas, todo ello a través de rutas específicas de señalización. ${ }^{7,8,11,12,15}$ Sin embargo, el significado de esta sobreexpresión en células tumorales aún no ha sido determinado por completo. Para el año 2011 se estimó que de 1.4 millones de casos de cáncer diagnosticados en los EEUU, aproximadamente 900,000 presentaron niveles elevados de MUC1. ${ }^{16}$ De manera interesante, se ha sugerido que las alteraciones en la superficie celular epitelial ocasionados por modificaciones en el microambiente extracelular podrían generar señales que estarían mediadas por el dominio citoplásmico de MUC1, con la colaboración de algunas moléculas reguladoras o efectoras que incluyen miembros de la familia de los RTKs tales como EGFR y ErbB2/Neu, tirosinas quinasa como c-Src y algunas moléculas de adhesión intracelular, las cuales regulan el crecimiento y la supervivencia celular y promueven la migración, diferenciación y transcripción. ${ }^{6,8,17}$ Otros estudios realizados en células epiteliales de glándula mamaria han propuesto que MUC1, a través de

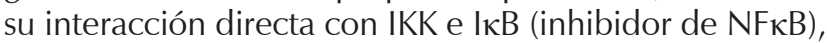
es capaz de activar la ruta de señalización del NFКB. ${ }^{6,18}$ De manera importante, estudios recientes realizados por Carson y colaboradores ${ }^{19}$ con líneas de células epiteliales de adenocarcinoma uterino y cáncer pancreático de humanos, demuestran que la activación de EGFR estimula la expresión de MUC1 y destacan la importancia de la regulación de la expresión de MUC1 como una estrategia terapéutica complementaria en tumores. Más aún, otro estudio previo realizado en células de glándula mamaria habría propuesto que MUC1 regulaba la localización y función en el núcleo del EGFR. ${ }^{20,21}$

En relación a la presencia y posible papel de MUC1 en la piel normal y en algunas patologías cutáneas, son muy pocos los estudios realizados hasta el presente. Algunos de ellos mostrando que MUC1 no es expresada por las células de la epidermis de piel normal, ${ }^{10,22,23}$ pero puede ser expresada por células epidermales en algunas lesiones inflamatorias como la psoriasis ${ }^{22}$ y queratosis actínica, ${ }^{23}$ así como en algunas lesiones premalignas que incluyen la epidermólisis bullosa ${ }^{10}$ y lesiones malignas tales como la enfermedad de Bowen, enfermedad de Paget y carcinoma de Merkel. ${ }^{10}$ Sin embargo, la expresión de MUC1 así como su posible papel en el CBC a nuestro entender, no ha sido considerada.

Basados en estas evidencias, el objetivo de este estudio ha sido investigar por métodos inmunohistoquímicos si MUC1 está presente en los engrosamientos epidérmicos observados en CBC. De igual manera, investigar la presencia y localización de c-Src, IKK $\alpha / \beta$, NFкB/p50p65, EGFR y ErbB2 en sus formas activadas o fosforiladas en las mismas biopsias, debido a que recientemente se ha sugerido que estas proteínas están muy relacionadas con la regulación de la expresión de MUC1 y su posible papel en diversos tipos de carcinomas. ${ }^{10,19-21}$

\section{MATERIAL Y MÉTODOS}

Para el estudio observacional, descriptivo y de corte transversal fueron seleccionadas ocho biopsias de pacientes diagnosticados clínica e histológicamente con CBC superficial. Todas obtenidas de los archivos de la Sección de Dermatopatología del Servicio Autónomo Instituto de Biomedicina (SAIB). La edad de los pacientes estuvo comprendida entre los 40 y 75 años. De igual manera, seis muestras de piel normal de humano de áreas no expuestas fueron obtenidas de pacientes que acudieron a un centro de cirugía estética para la realización de procedimientos reconstructivos y cuyas edades estaban comprendidas entre los 20 y 50 
años. Todas ellas, con el consentimiento informado de los pacientes y de acuerdo con los principios de la Declaración de Helsinki y con las normas del Comité de Ética del SAIB.

Las biopsias fueron procesadas siguiendo la metodología convencional. Todas las secciones desparafinadas fueron procesadas para tinción con H\&E.

\section{Inmunofluorescencia indirecta}

Para la inmunotinción, secciones seriadas de $4 \mu \mathrm{m}$ de espesor fueron desparafinadas en xilol y deshidratadas en una serie de concentraciones decrecientes de etanol y equilibradas en PBS por 10 min. Las inespecifícidades de los anticuerpos fueron bloqueadas, incubando las secciones en PBS conteniendo 2\% de albúmina de suero bovino (BSA) por 1 hora a temperatura ambiente. Seguidamente, las secciones fueron incubadas toda la noche en una cámara húmeda a $4{ }^{\circ} \mathrm{C}$ con un anticuerpo monoclonal anti-MUC1 de humano (clone BC2) preparado en ratón, mientras que otras secciones obtenidas de algunas de estas biopsias fueron incubadas de igual manera con un anticuerpo policlonal anti-fosfo NFkBp65 (Ser536), un anticuerpo policlonal anti-fosfo NFkBp50 (Ser337), un anticuerpo policlonal anti-fosfo-IKK $\alpha / \beta$ (Ser180/Ser181) todos estos preparados en conejo, un anticuerpo monoclonal anti-IKK $\alpha$ no fosforilado preparado en ratón, un anticuerpo monoclonal anti-fosfo c-Src (Tyr419) o un anticuerpo monoclonal anti-tubulina acetilada, estos últimos preparados en ratón (Santa Cruz Biotechnology, Santa Cruz, CA). Después de lavados sucesivos en PBS, un anticuerpo secundario Alexa Fluor 488 anti-ratón, un anticuerpo secundario Alexa fluor 594 anti-conejo o un anticuerpo secundario Alexa Fluor 488 anti-cabra (Invitrogen, Molecular Probes, OR) fueron aplicados por $30 \mathrm{~min}$ a temperatura ambiente, manteniendo las secciones en la oscuridad. Luego, las mismas fueron lavadas nuevamente en PBS y cubiertas con medio montante Immu-mount (Shandon, Pittsburg, PA). Los controles negativos fueron producidos omitiendo el anticuerpo primario y colocando en su lugar PBS. Las imágenes fueron capturadas con un microscopio invertido Olympus IX81 (Fluo View) (Olympus America Inc) configuración láser de barrido.

\section{Inmunoperoxidasa}

Para evaluar las características proliferativas de la epidermis hiperplásica, se aplicó la técnica de avidina-biotina peroxidasa. Para ello, las secciones fueron desparafinadas en xilol, deshidratadas en una serie de concentraciones decrecientes de etanol (100 a 70\%) y equilibradas en PBS por 10 min.
Luego tratadas con una solución recuperadora de antígenos (Dako Cytomation) e incubadas con un anticuerpo monoclonal Ki-67 de humano producido en ratón (clon MIB-1, Dako Cytomation) por 30 min a temperatura ambiente. Las secciones fueron reveladas usando el sistema EnVision Flex (Dako Cytomation) y contrastadas con hematoxilina de Mayer. Las secciones fueron examinadas con un microscopio invertido (IX70 Olympus, Olympus America Inc, Melville, NY). Las imágenes fueron capturadas usando el software Image-Pro Plus, Media Cybernetics, Silver Spring, MD).

De igual manera, para investigar la presencia de EGFR y ErbB2/Neu en algunas secciones de CBC superficial y piel normal, también se aplicó la técnica de avidina-biotina peroxidasa usando un anticuerpo policlonal anti-fosfo EGFR (Tyr845) o anti-ErbB2 (Tyr877). Para ello los cortes fueron lavados con PBS pH 7.4 durante 30 minutos. Para bloquear la peroxidasa endógena, los cortes fueron incubados con peróxido de Hidrógeno $\left(\mathrm{H}_{2} \mathrm{O}_{2}\right)$ a $3 \%$ durante cinco minutos a temperatura ambiente. Luego de lavados con PBS pH 7.4 se llevó a cabo el bloqueo de inespecifícidades, con $2 \%$ de BSA por una hora. Los cortes fueron incubados toda la noche a $4{ }^{\circ} \mathrm{C}$ con los anticuerpos primarios correspondientes. Después de varios lavados en PBS, un anticuerpo secundario Biotinilado (Dako Cytomation) fue aplicado por 15 minutos a temperatura ambiente, seguido por el complejo estreptavidina-HRP (Dako Cytomation), también por 15 minutos. El revelado se realizó por un minuto utilizando una solución sustrato-cromógeno $\left(\mathrm{H}_{2} \mathrm{O}_{2}\right.$-cromógeno) (Dako Cytomation). Finalmente, las láminas fueron contrastadas con hematoxilina de Mayer y se les colocó una gota de medio montante (Aquaperm TM). Los cortes fueron observados y analizados en un microscopio invertido Olympus IX-70. Las imágenes obtenidas fueron capturadas utilizando el programa Image-Pro Plus (Image-Pro Plus, Media Cybernetics, MD). Los controles negativos fueron realizados utilizando PBS en lugar del anticuerpo primario.

\section{RESULTADOS}

\section{Inmunolocalización in vivo de Ki-67 en CBC}

En este estudio, la presencia de Ki-67, una proteína nuclear expresada en células proliferativas, fue evaluada en la epidermis engrosada y en zonas adyacentes en algunas de las biopsias de pacientes con diagnóstico de CBC superficial.

Consistente con estudios previos, se encontró una expresión nuclear elevada en las células basales y suprabasales de los engrosamientos epidérmicos (Figura 1A). En contraste, esta expresión nuclear aparecía disminuida en las zonas adyacentes al engrosamiento (Figura 1B). 


\section{Presencia in vivo de MUC1 en CBC}

Debido a que la expresión de MUC1 parece estar limitada a la superficie apical de muchas células epiteliales normales para protegerlas de las condiciones adversas, ${ }^{8}$ y debido a que esta glicoproteína transmembrana está sobreexpresada en diversos tipos de carcinoma, ${ }^{6-12}$ en este estudio investigamos por inmunofluorescencia si MUC1 estaba presente en biopsias de pacientes con diagnóstico de CBC superficial que exhibían la epidermis engrosada o hiperplásica.

El contraste por interferencia diferencial y la inmunofluorescencia, ambos analizados por microscopia confocal, reveló una fuerte inmunoreactividad para MUC1, la cual fue detectada en la superficie apical de algunas células basales y suprabasales, así como también distribuida por completo alrededor de las células que estaban orientadas hacia la dermis papilar, posiblemente migrando e invadiendo esa región (Figuras $2 A$ y $B$ ). En contraste, ninguna inmunopositividad para MUC1 fue hallada en la epidermis, las muestras de piel normal (Figuras 2C y D), ya que la misma estaba restringida a la dermis, específicamente a algunos fibroblastos y microvasos (Figuras $2 \mathrm{C}$ y D). Adicionalmente, ninguna inmunopositividad fue detectada cuando el anticuerpo primario fue omitido o reemplazado por PBS (control negativo).

\section{Inmunolocalización in vivo de NFкBp65, NFKBp50 e IKKa//}

Para determinar si la expresión de MUC1 en CBC podría también estar asociada a la activación y translocación

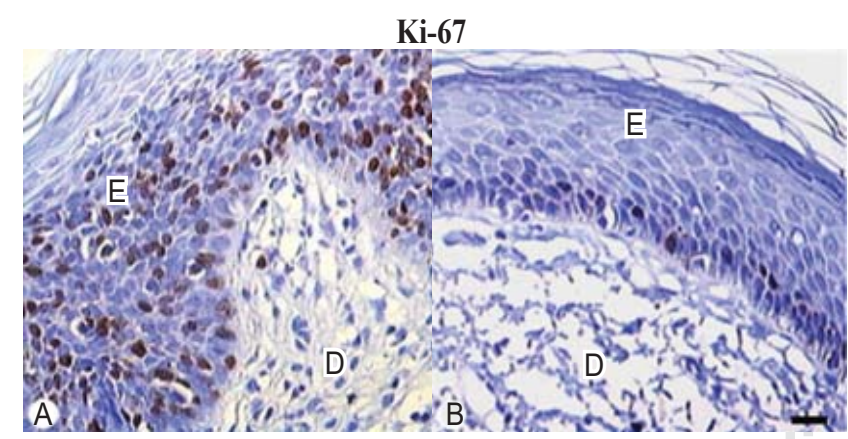

Figura 1: Inmunolocalización de Ki-67 en un corte longitudinal desparafinado de un carcinoma basocelular superficial mostrando la epidermis engrosada (A) y una zona adyacente (B). Una fuerte expresión nuclear es observada en muchas de las células basales y suprabasales de la epidermis engrosada (A), mientras que una expresión muy disminuida es observada en las células de la capa basal en la zona adyacente (B). Barra $=30 \mu \mathrm{m}$. $E=$ epidermis $; D=$ dermis .

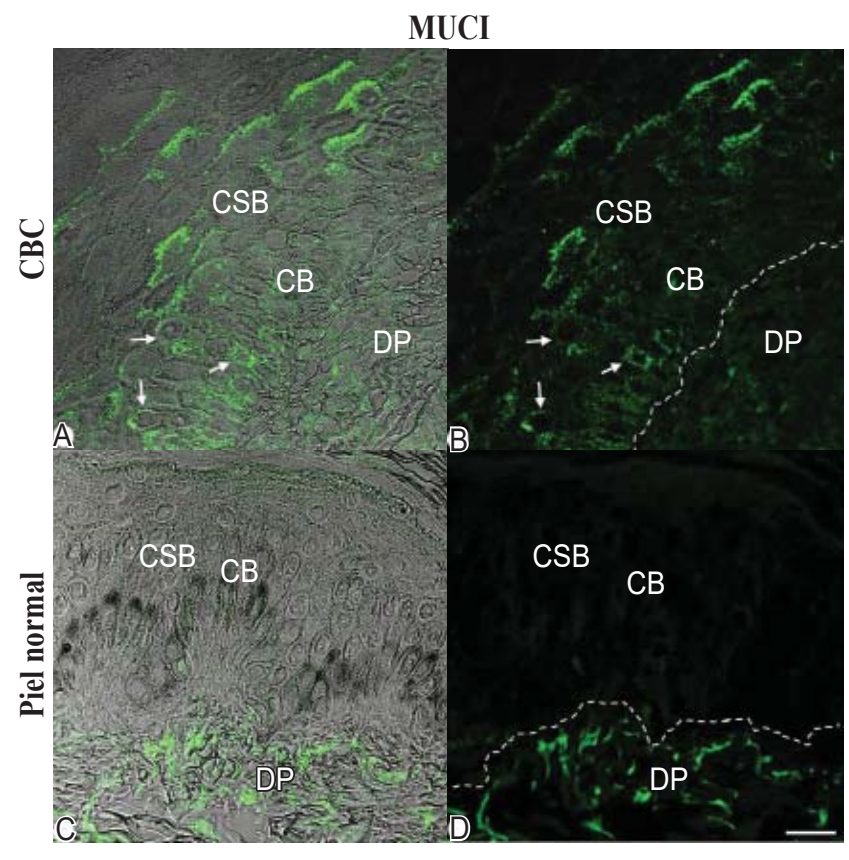

Figura 2: Superposición de imágenes de microscopia de interferencia diferencial (A y C) e imágenes de fluorescencia (B y D) obtenidas con un microscopio confocal en cortes desparafinados de una zona de un $C B C$ superficial, exhibiendo la epidermis engrosada (A y B) y de una zona de piel normal (C y D) inmunomarcadas con anti-MUC1. Una fuerte inmunopositividad para MUC1 es detectada en la superficie apical de algunas células basales (CB) y suprabasales (CSB), así como también distribuida por completo alrededor de las células orientadas hacia la dermis papilar (A y B, flechas). Observe que ninguna inmunoreactividad para MUC1 es detectada en la epidermis de las biopsias obtenidas de piel normal (C y D). Barra $=20 \mu \mathrm{m}$.

nuclear del NFkB, en este estudio examinamos por inmunofluorescencia si las formas activadas o fosforiladas

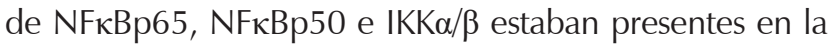
epidermis de algunos CBC superficial donde MUC1 fue detectada y en la epidermis de pacientes normales. Para ello un anticuerpo que reconoce la forma fosforilada de la subunidad p65 (Ser536), un anticuerpo que reconoce la forma fosforilada de la subunidad p50 (Ser337) y otro que reconoce las formas fosforiladas de IKK $\alpha$ e IKK $\beta$ (Ser180/181) fueron utilizados. Ambos, p-p65 y p-p50, fueron seleccionados ya que ellos son las unidades del $N F \kappa B$ más frecuentemente detectadas en tejidos de humanos.

El examen de las biopsias de CBC reveló una inmunorreactividad moderada para p-p65 en el citoplasma de las células basales y suprabasales (Figura 3A), así como en el núcleo de algunas de ellas; esta última localización sugestiva de la activación y translocación del 

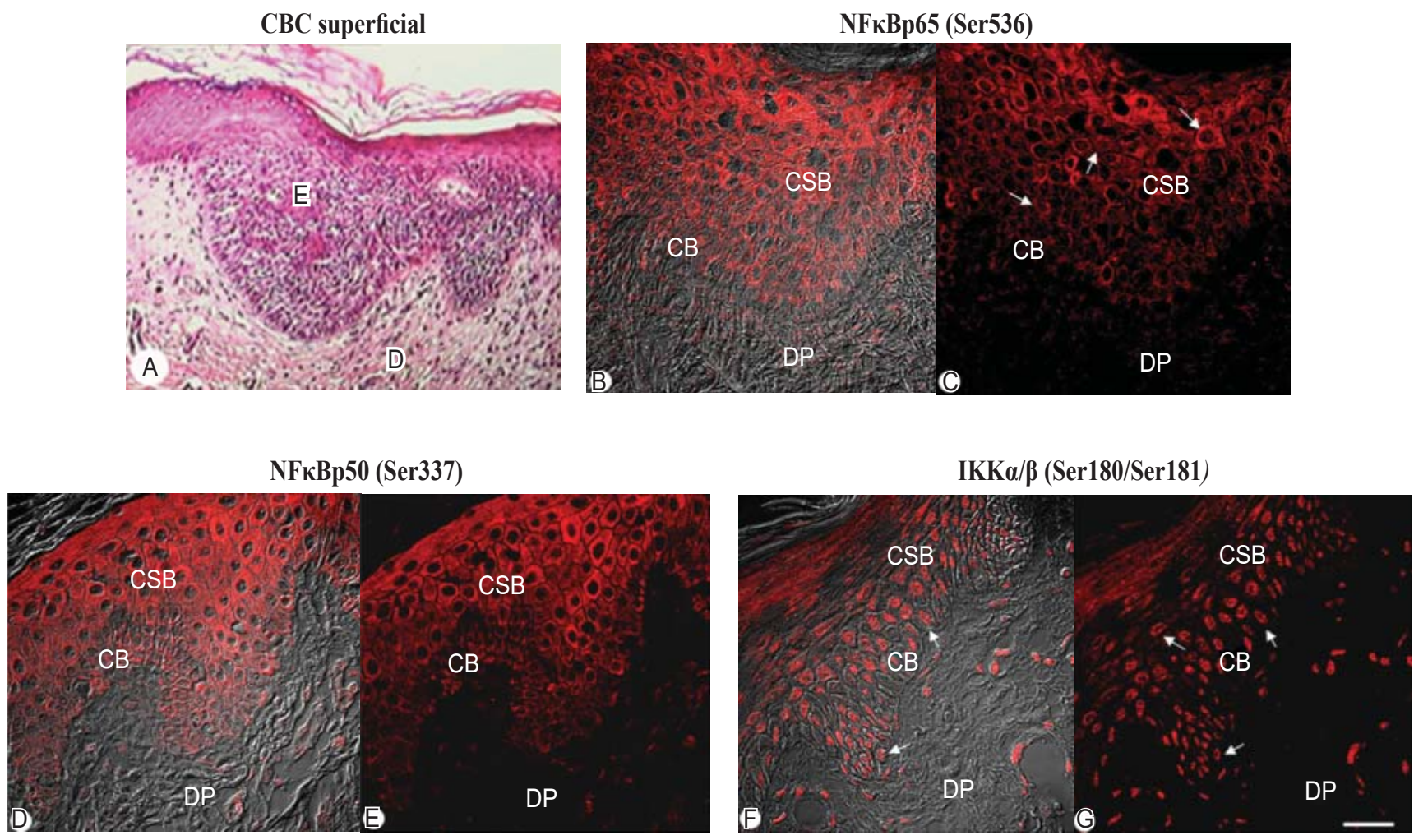

Piel normal

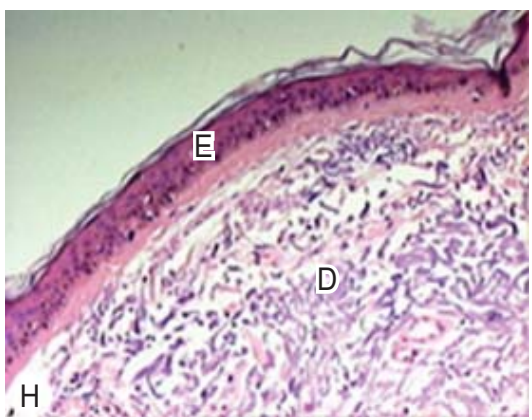

IKKa/ß (Ser180/Ser181)

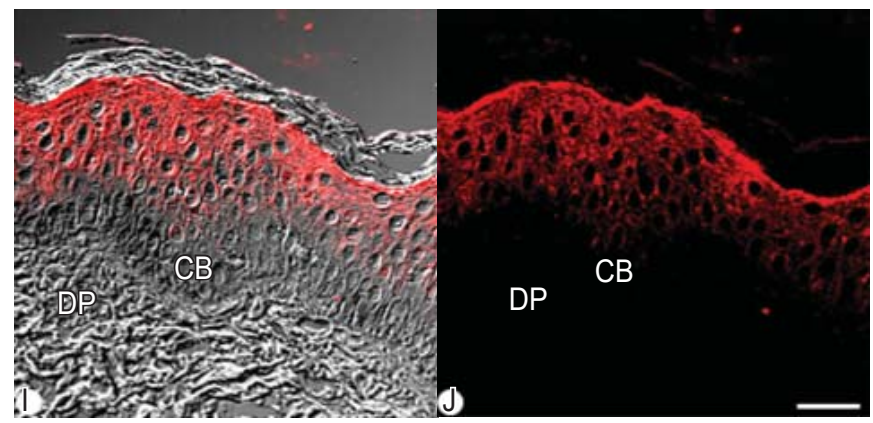

Figura 3: (A) Corte desparafinado y contrastado con $H \& E$ de una zona de un carcinoma basocelular (CBC) superficial, exhibiendo la epidermis engrosada (E). D, dermis. Superposición de imágenes de microscopia de interferencia diferencial $(B, D, F)$ e imágenes de fluorescencia $(C$, $E, G)$ obtenidas con un microscopio confocal de cortes desparafinados de una zona de un CBC superficial exhibiendo la epidermis engrosada, inmunomarcada con NFkBp65 (Ser536) (B, C), con NFkBp50 (Ser337) (D, E), y con IKKa/B (Ser180/Ser181) (F, G). Una moderada inmunoreactividad para p-p65 es observada en el citoplasma de las células basales (CB) y suprabasales (CSB), así como también en el núcleo de algunas de ellas (B, C, flechas). Para p-p50 una inmunoreactividad es observada mayormente en el citoplasma de algunas células basales y suprabasales $(D, E)$, Notablemente, una fuerte inmunoreactividad para $p$-IKK $\alpha / \beta$ es detectada en el núcleo de muchas células basales $y$ suprabasales (F y G, flechas). Barra $=40 \mu m$. (H) Corte desparafinado y contrastado con $H \& E$ de una zona de piel normal. E, epidermis; $D$, dermis. (I, J) Superposición de imágenes de una zona de piel normal inmunomarcada con IKKa/ß (Ser180/Ser181). Una fuerte inmunoreactividad para esta proteína es detectada mayormente en el citoplasma de las células basales (CB) y suprabasales (CSB). Note que ninguna inmunoreactividad nuclear es observada. Barra $=40 \mu \mathrm{m}$. 
NFкB (Figuras $3 B$ y C). Para p-p50, una inmunorreactividad fue observada mayormente en el citoplasma de algunas células basales y suprabasales (Figuras 3D y E). De manera interesante, para $p-I K K \alpha / \beta$ una fuerte inmunorreactividad fue detectada en el núcleo de muchas células basales y suprabasales (Figuras 3F y G), mientras que una inmunorreactividad moderada restringida al citoplasma de estas células fue observada cuando se utilizó un anticuerpo que reconocía la forma no activada o no fosforilada de IKK $\alpha$. Cuando la presencia de $p$-IKK $\alpha / \beta$ fue evaluada en la epidermis de algunas muestras de piel normal (Figura 3H), encontramos que ellas estaban presentes mayormente en el citoplasma de las células basales y suprabasales (Figuras 31 y 3 J). Resultados similares fueron obtenidos cuando utilizamos IKK $\alpha$ en su forma no fosforilada.

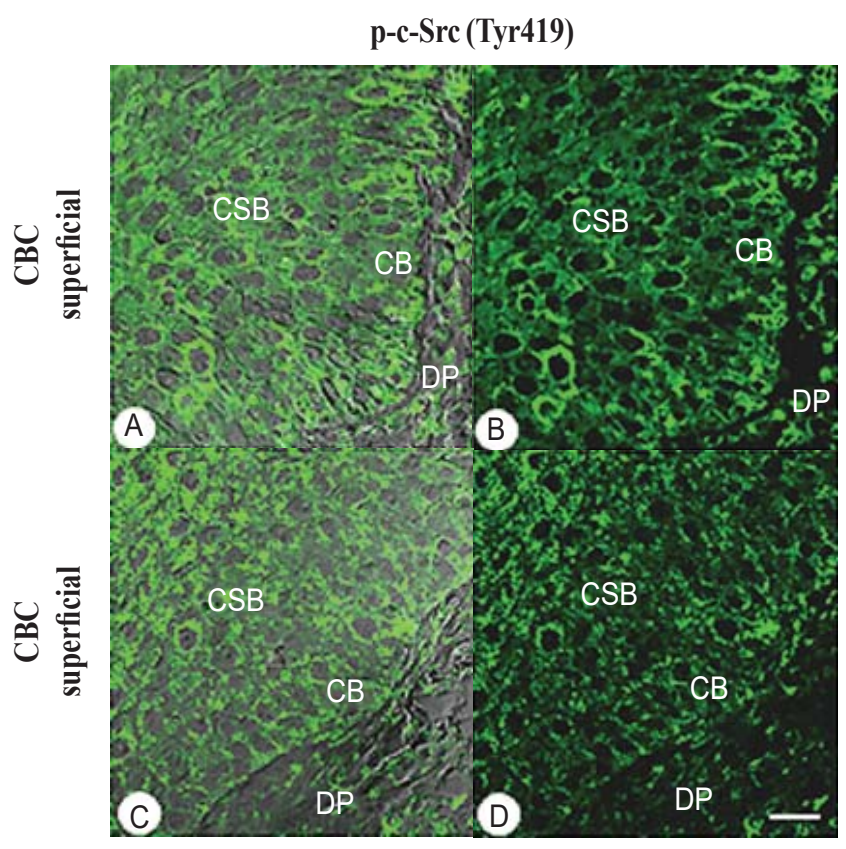

Figura 4: Superposición de imágenes de microscopia de interferencia diferencial $(A, C)$ e imágenes de fluorescencia $(B, D)$ obtenidas con un microscopio confocal de cortes desparafinados de una zona de un carcinoma basocelular $(C B C)$ superficial exhibiendo la epidermis engrosada, inmunomarcadas con anti-fosfo-c-Src (Tyr419) (A, B) y anti-tubulina $(C, D)$. Una fuerte inmunoreactividad para p-c-Src es observada en los márgenes, puentes intercelulares y citoplasma de las células suprabasales (CSB), así como en las células basales (CB), particularmente en aquellas orientadas hacia la dermis papilar (DP) (A, B). El inmunomarcaje para tubulina revela que la organización de los MTs está alterada en las células basales y suprabasales de las biopsias de $C B C(C, D)$. Barra $=30 \mu m$.

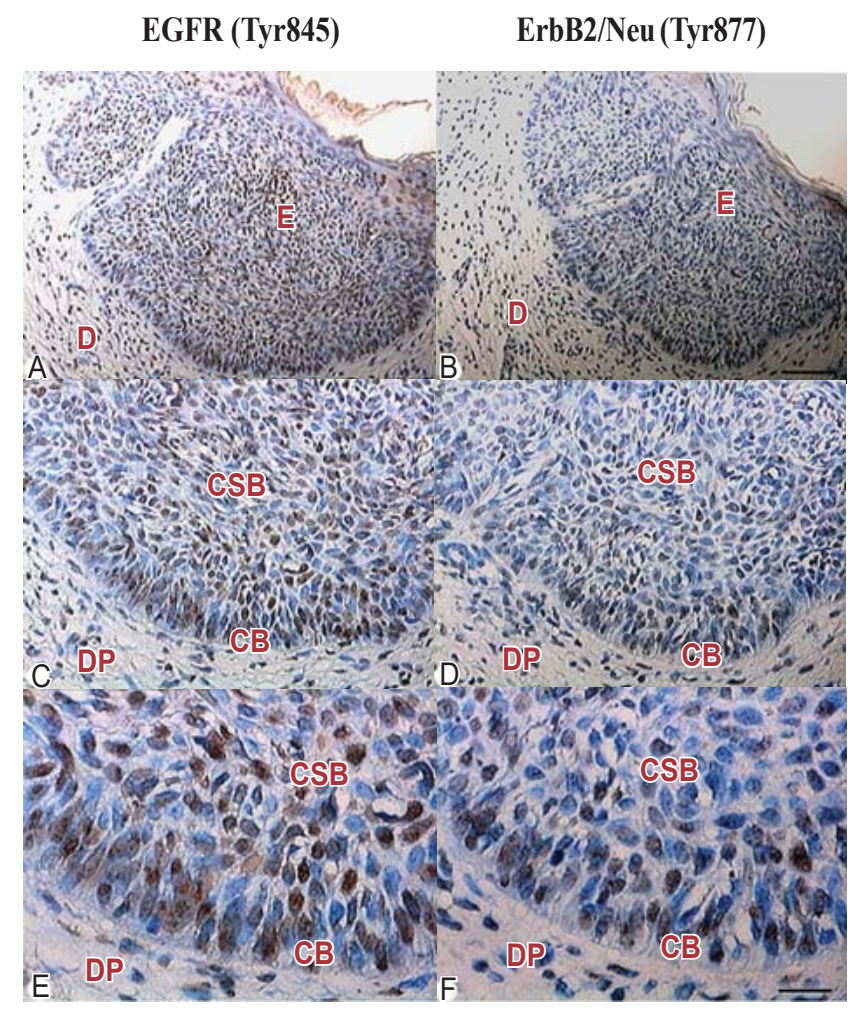

Figura 5: Inmunolocalización de p-EGFR (Tyr845) y p-ErbB2 (Tyr877) en secciones seriadas desparafinadas de un carcinoma basocelular (CBC) superficial mostrando la epidermis engrosada (A-F). Para p-EGFR una fuerte inmunoreactividad nuclear es observada en muchas de las células basales (CB) y suprabasales (CSB) de los engrosamientos epidérmicos (A, $C, E)$. Para p-ErbB2 el inmunomarcaje es menos intenso comparado con el observado para p-EGFR. Barra=160 $\mu m(A, B) ; 40 \mu m(C, D) ; 25 \mu m(E, F)$.

\section{Inmunolocalización in vivo de p-c-Src y tubulina}

En vista de estos hallazgos, y debido a que una interacción fisiológica entre c-Src y el complejo IKK que favorece la activación de $\mathrm{NF} \kappa \mathrm{B}$ ha sido propuesta, ${ }^{24}$ y debido a que c-Src se localiza asociada físicamente a los microtúbulos (MTs), ${ }^{24,25}$ decidimos investigar por inmunofluorescencia si la forma activada de c-Src estaba presente en las biopsias de CBC donde la expresión de MUC1 y de IKK $\alpha / \beta$ activados fue evidente.

La inmunolocalización con anti-fosfo-c-Src (p-c-Src) (Tyr419) demostró que esta proteína aparecía concentrada en los márgenes, puentes intercelulares y citoplasma de las células basales y suprabasales, así como también en los lamelipodios de aquellas células basales que estaban orientadas hacia la dermis papilar (Figuras $4 A$ y B). Respecto a los MTs, la inmunolocalización de la tubulina, un componente 
esencial de los MTs, reveló que la organización de éstos estaba alterada en las células basales y suprabasales (Figuras 4C y D). Específicamente, esta proteína fue observada en los márgenes de las células basales y suprabasales.

\section{Inmunolocalización in vivo de EGFR y ErbB2/Neu}

Estudios previos han sugerido que c-Src también regula la activación de EGFR ${ }^{26}$ asimismo, trabajos recientes han señalado que EGFR estimula la expresión de MUC1. ${ }^{19}$ Por lo tanto, en este estudio también investigamos la presencia de EGFR y ErbB2/Neu en sus formas activadas en algunas de las biopsias de CBC, donde MUC1 y fosfo-C-Src (Tyr419) estaban presentes. Para ello, un anticuerpo que reconoce la forma fosforilada de EGFR ( $p$-EGFR (Tyr845) y otro que reconoce la de ErbB2/Neu (p-ErbB2 (Tyr877) fueron utilizados.

La técnica de inmunoperoxidasa reveló una fuerte inmunorreactividad nuclear para p-EGFR en muchas de las células basales y suprabasales de los engrosamientos epidérmicos (Figuras 5A, C y E). Para p-ErbB2, la inmunorreactividad fue menos intensa comparada con la observada para p-EGFR (Figuras 5B, D y F). Ninguna inmunorreactividad fue observada cuando el anticuerpo primario fue omitido (Fig. no mostrada).

\section{DISCUSIÓN}

El presente estudio in vivo demuestra la presencia de MUC1 en los engrosamientos epidérmicos observados en todas las biopsias evaluadas de pacientes con diagnóstico de CBC superficial.

En efecto, una fuerte expresión de MUC1 fue hallada en la superficie apical de algunas células basales y suprabasales, mientras que en otras, esta expresión aparecía distribuida por completo alrededor de las células que parecían estar migrando hacia la dermis papilar. Notablemente, una inmunorreactividad para MUC1 muy similar fue observada en tres biopsias de pacientes con diagnóstico de CBC morfeiforme, las cuales no fueron consideradas para este estudio. Es importante destacar que en la epidermis de piel normal MUC1 no fue evidenciada. Consistente con estos hallazgos, estudios previos han revelado que las células de la epidermis normal no expresan MUC1, 10,22,23 pero que ésta es expresada por algunas células epidérmicas en lesiones cutáneas inflamatorias como la psoriasis ${ }^{22}$ y queratosis actínica, ${ }^{23}$ así como también en algunas lesiones premalignas como epidermólisis bullosa y malignas que incluyen la enfermedad de Paget y carcinoma de Merkel. ${ }^{10}$ Sin embargo, como lo indican los mismos estudios, las funciones de MUC1 en estas lesiones cutáneas no han sido dilucidadas. En este contexto, algunos estudios previos in vivo e in vitro en células epiteliales normales y transformadas han demostrado que MUC1 suele estar localizada en la cara apical de las células epiteliales secretoras normales y que cuando las células pierden su polaridad, ella aparece localizada sobre toda la superficie celular. ${ }^{6,8,27,28} \mathrm{De}$ manera interesante, los mismos estudios sugieren que la sobreexpresión de MUC1 reduce significativamente las interacciones célula-célula y las interacciones célulamatriz extracelular, favoreciendo por lo tanto la motilidad y migración celular. ${ }^{8,27,28}$ En este mismo orden de ideas, estudios recientes relacionados con la localización de MUC1 en carcinoma proponen que su presencia en toda la membrana plasmática y/o en el citoplasma de las células epiteliales está muy relacionada con la capacidad invasiva y la supervivencia de las células epiteliales transformadas. ${ }^{9}$ Respecto al posible papel de MUC1 durante las condiciones benignas y malignas, estudios recientes han puntualizado que MUC1 funciona como un sensor molecular y transductor de señales en respuesta a estímulos externos que dan lugar a ciertos eventos celulares que incluyen la síntesis y secreción de factores de crecimiento y citocinas, proliferación, pérdida de la polaridad celular, separación, migración y supervivencia. ${ }^{7,8,11,12,15}$ En cuanto al papel de MUC1 en la migración celular, se ha sugerido que esta glicoproteína juega un papel importante en la reorganización del citoesqueleto ocurrida durante la migración, donde no receptores tirosinas quinasas como c-Src parecen estar implicadas. ${ }^{29}$ Por lo tanto, es posible asumir que la presencia de MUC1 en la superficie apical y distribuida por completo alrededor de la membrana plasmática de algunas células basales y suprabasales que están orientadas hacia la dermis papilar, podría representar una respuesta de estas células a ciertos factores predisponentes para el desarrollo y la progresión del CBC tales como la exposición prolongada a las radiaciones $U V$, niveles elevados de factores de crecimiento o citocinas y edad avanzada, entre otros, ${ }^{1,2}$ respuesta que se evidencia en la pérdida de las interacciones célula-célula y, por consiguiente, en los cambios en la polaridad celular que podrían favorecer la migración e invasión colectiva de estas células, como suele ocurrir en la progresión de muchos tumores ${ }^{30}$ y en la progresión del CBC, donde CD44 y c-Src parecen estar involucrados. ${ }^{31}$ Más aún si tomamos en cuenta que MUC1 no fue hallada en la epidermis de piel normal.

En este trabajo también encontramos que las formas

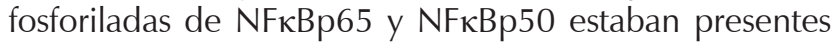


en los engrosamientos epidérmicos donde MUC1 fue detectada. Estos hallazgos son interesantes si consideramos que el heterodímero p65/p50 es un factor de transcripción que ha sido involucrado en la expresión de algunos genes relacionados con eventos celulares importantes tales como proliferación celular, migración y supervivencia, y que la activación de NFKB estimula la expresión de MUC1 en células no malignas y malignas, particularmente NFkBp65.6,18,32 De manera importante, en este estudio detectamos que la forma fosforilada de $I K K \alpha / \beta$, un complejo que regula la activación de $\mathrm{NF \kappa B}$ tanto en condiciones fisiológicas como patológicas, estaba localizada en el núcleo de la mayoría de las células basales y suprabasales, particularmente en aquéllas que parecían estar migrando hacia la dermis papilar, mientras que en la epidermis de algunas muestras obtenidas de piel normal las mismas fueron detectadas en el citoplasma de las células basales y suprabasales. A este respecto, algunos estudios han indicado que IKK $\alpha$, cuando está activado, puede ser detectado en el citoplasma y en el núcleo, mientras que IKK $\beta$ es detectado predominantemente en el citoplasma, ${ }^{33,34}$ sugiriendo que IKK $\alpha$ nuclear contribuye a la transactivación de NFKB por una ruta no canónica y regulando la transcripción de algunos genes. Otros estudios han reportado la presencia de IKK $\alpha$ nuclear en distintos tipos de cáncer, sugiriendo un papel para esta molécula durante el ciclo celular y la apoptosis. ${ }^{34}$ No obstante, las implicaciones de la localización nuclear de IKKa sigue siendo materia de debate.

En este estudio, también investigamos la presencia y localización de la forma activada de c-Src (Tyr419) en los queratinocitos de algunos $\mathrm{CBC}$, y si su activación podría estar asociada con cambios en la organización de los MTs, particularmente tubulina, tomando en cuenta que la activación del complejo IKK al parecer es llevado a cabo por c-Src activado, contribuyendo de esta manera a la transactivación de $\mathrm{NF}_{\mathrm{K}} \mathrm{B}^{24}$ y que c-Src se localiza asociado físicamente a los MTs. ${ }^{25,35}$ De manera interesante, encontramos que en aquellas biopsias donde la expresión de MUC1 e IKK $\alpha / \beta$ era evidente, c-Src (Tyr419) aparecía concentrada en los márgenes, puentes intercelulares y citoplasma de las células basales y suprabasales que se observaban orientadas hacia la dermis y que la organización de los MTs en esas células estaba alterada como ha sido reportada en placa psoriática. ${ }^{22} \mathrm{~A}$ este respecto, estudios puntuales realizados en células epiteliales transformadas han propuesto que la alteración de los MTs ocasionada por una variedad de señales que incluyen estímulos mecánicos, radiaciones y factores de crecimiento, también es crucial para el transporte y translocación del NFkB al núcleo y el control de la expresión de varios genes que son regulados por este factor de transcripción, ${ }^{36}$ y que esta activación requiere de la presencia de c-Src ${ }^{24,25}$ y del complejo IKK, ambos activados, los cuales parecen estar asociados a los MTs. ${ }^{24}$ Sin embargo, una conexión entre esas distintas respuestas y el CBC no ha sido explorada.

Finalmente, es conocido que la activación del EGFR está implicada en la renovación normal de la epidermis, regeneración después de un daño, respuesta inmune y carcinogénesis ${ }^{3-5}$ y que en células epiteliales normales y tumorales la fosforilación del residuo Tyr845 en el dominio quinasa de EGFR y del residuo Tyr877 del ErbB2, en ausencia de ligandos requiere de la presencia de c-Src activado. También la presencia de estos RTKs en sus formas activadas o fosforiladas en el núcleo de células epiteliales normales y tumorales, ha sido relacionada con la activación y transcripción de algunos genes y posiblemente otros eventos nucleares. ${ }^{37}$ En este mismo orden de ideas, un estudio reciente llevado a cabo por el grupo de Carson ${ }^{19}$ con líneas de células epiteliales de carcinoma uterino y cáncer pancreático de humanos ha reportado que la activación y translocación de EGFR al núcleo estimula la expresión de MUC1, sugiriendo que la sobreexpresión de MUC1 realza las funciones protectivas de ciertas lesiones malignas. ${ }^{19}$ Por lo tanto, en este estudio también investigamos la presencia y distribución de EGFR y ErbB2/ Neu en algunas de las biopsias con diagnóstico de CBC superficial. De manera interesante, las formas fosforiladas de EGFR y ErbB2/Neu fueron detectadas en el núcleo de muchas células basales y suprabasales que parecían estar migrando hacia la dermis papilar. Notablemente, la presencia de MUC1 había sido detectada en la superficie apical y alrededor de algunas células basales y suprabasales de los engrosamientos epidérmicos. De acuerdo con estas observaciones y las mencionadas previamente, es posible especular que una eventual estimulación de la producción de MUC1 en CBC superficial podría estar condicionada por la activación y translocación de EGFR/ErbB2, esta última promovida por c-Src.

Consistente con nuestras observaciones y los estudios mencionados aquí, proponemos que la estimulación de los queratinocitos (por exposición a las radiaciones UV, daño mecánico, factores de crecimiento o citocinas) puede causar alteraciones en el citoesqueleto, particularmente en los MTs y por lo tanto la activación de aquellas moléculas asociadas a éstos, como c-Src e IKKa, conduciendo a la activación y translocación de NFкB. Una vez en el núcleo, NFKB podría favorecer la expresión de MUC1. Luego de instalada en la membrana plasmática, MUC1 participaría en algunas respuestas celulares tales como la proliferación, 
pérdida de las interacciones célula-célula, motilidad, migración y supervivencia de los queratinocitos.

Adicionalmente, es posible que c-Src una vez activado vía MTs, afectara la interacción queratinocito-queratinocito activando a EGFR y Neu, los cuales una vez activados serían translocados al núcleo donde eventualmente podrían regular la expresión de MUC1.

Finalmente, consideramos que nuestros datos, junto con aquéllos aportados por otros, podrían representar un marco de referencia importante para lograr un mejor entendimiento de algunas lesiones cutáneas, particularmente el CBC.

\section{CONCLUSIONES}

Basados en nuestras observaciones y estudios previos, proponemos que la estimulación de los queratinocitos (por exposición a las radiaciones UV, daño mecánico, factores de crecimiento o citocinas) podría activar aquellas moléculas, como c-Src e IKKa, que favorecen la activación y translocación de NFאB y la eventual expresión de MUC1. Una vez expresada, MUC1 estaría participando en algunas respuestas celulares como la proliferación, pérdida de las uniones intercelulares, motilidad, migración y supervivencia de los queratinocitos.

Financiación: Este estudio ha sido financiado por el Servicio Autónomo Instituto de Biomedicina (SAIB).

Correspondencia:
Enrique Arciniegas
Facultad de Medicina,
Universidad Central de Venezuela.
Distrito Capital, Caracas-1010.
Fax: 582128626807
E-mail: earciniegasbeta@yahoo.com

\section{BIBLIOGRAFÍA}

1. Kasper M, Jaks V, Hohl D, Toftgård R. Basal cell carcinoma molecular biology and potential new therapies. J Clin Invest. 2012; 122: 455-563.

2. Crowson AN. Basal cell carcinoma: biology, morphology and clinical implications. Modern Pathol. 2006; 19: S127-S147.

3. López-Camarillo C, Aréchaga E, López M, Pérez-Plasencia C, Alvarez-Sánchez E, Marchat LA. Protein kinases and transcription factors activation in response to UV radiation of skin: Implications for carcinogenesis. Int J Mol Sci. 2012; 13: 142-172.

4. Pastore S, Mascia F, Mariani V, Girolomoni G. The epidermal growth factor receptor system in skin repair and inflammation. J Invest Dermatol. 2008; 128: 1365-1374.

5. El-Abaseri TB, Putta S, Hansen LA. Ultraviolet irradiation induces keratinocyte proliferation and epidermal hyperplasia through the activation of the epidermal growth factor receptor. Carcinogenesis. 2006; 27: 225-231.

6. Kufe D. MUC1-C oncoprotein as a target in breast cancer activation of signaling pathways and therapeutic approaches. Oncogene. 2013; 32: 1073-1081.

7. Baldus SE, Engelmann K, Hanisch FG. MUC1 and the MUCs: A family of human mucins with impact in cancer biology. Crit Rev Clin Lab Sci. 2004; 41: 189-231.

8. Hollingsworth MA, Swanson BJ. Mucins in cancer: protection and control of the cell surface. Nat Rev Cancer. 2004; 4: 45-60.

9. Horm TM, Schroeder JA. MUC1 and metastatic cancer. Expression, function and therapeutic targeting. Cell Adhesion Migration. 2013; 7: 1-12.

10. Chakraborty S, Bonthu N, Swanson B, Batra SK. Role of mucins in the skin during benign and malignant conditions. Cancer Lett. 2011; 301: 127-141

11. Liu X, Wen Y, Radhakrishnan P, Tremayne JR, Dao T, Johnson $\mathrm{KR}$ et al. Interactions between MUC1 and $\mathrm{p} 120$ catenin regulate dynamic features of cell adhesion, motility, and metastasis. Cancer Res. 2014; 74: 1609-1620.
12. Chugh S, Gnanapragassam VS, Jain M, Rachagani S, Ponnusamy MP, Batra SK. Pathobiological implications of mucin glycans in cancer: sweet poison and novel targets. Biochim Biophys Acta. 2015; 1856: 211-225.

13. Martinez-Sáez N, Peregrina JM, Corzana F. Principles of mucin structure: Implications for the rational design of cancer vaccines derived from MUC1-glycopeptides. Chem Soc Rev. 2017; 46: 7154-7175

14. Jain S, Stroopinsky D, Yin L, Rosenblatt J, Alam M, Bhargava $P$ et al. Mucin 1 Is a potential therapeutic target in cutaneous T-cell lymphoma. Blood. 2015; 126; 354-362.

15. Kufe DW. Mucins in cancer; function, prognosis, and therapy. Nat Rev Cancer. 2009; 9: 874-885.

16. Panchamoorthy G, Rehan H, Kharbanda A, Ahmad R, Kufe D. A monoclonal antibody against the oncogenic mucin 1 cytoplasmic domain. Hybridoma. 2011; 30: 531-535.

17. Singh PK, Hollingsworth MA. Cell surface-associated mucins in signal transduction. Trends Cell Biol. 2006; 16: 467-476.

18. Ahmad R, Raina D, Joshi MD, Kawano T, Ren J, Kharbanda $S$ et al. MUC1-C oncoprotein functions as a direct activator of the nuclear factor-kappaB p65 transcription factor. Cancer Res. 2009; 69: 7013-721.

19. Dharmaraj N, Engel BJ, Carson DD. Activated EGFR stimulates MUC1 expression in human uterine and pancreatic cancer cell lines. J Cell Biochem. 2013; 114: 2314-2322.

20. Bitler BG, Goverdhan A, Schroeder JA. MUC1 regulates nuclear localization and function of the epidermal growth factor receptor. J Cell Sci. 2010; 123: 1716-1723.

21. Piyush T, Chacko AR, Sindrewicz P, Hilkens J, Rhodes JM, Yu L-G. Interaction of galectin-3 with MUC1 on cell surface promotes EGFR dimerization and activation in human epithelial cancer cells. Cell Death Diff. 2017; 24: 1937-1947.

22. Arciniegas E, Carrillo LM, Páez E, Rojas H, Ramirez R, Reales E, Chopite M. Presence of MUC1 in the epidermal thickening of psoriatic plaques. Hist Histopathol. 2015; 30: 453-463. 
23. Arciniegas E, Carrillo LM, Rojas H, Ramirez R, Reyes O, Suárez A et al. Mucin1 expression in focal epidermal dysplasia of keratosis actinic. Ann Transl Med. 2015; 3: 1-9.

24. Funakoshi-Tago M, Tago K, Andoh K, Sonoda Y, Tominaga $\mathrm{S}$, Kasahara TJ. Functional role of c-Src in IL-1-induced NFkappa $B$ activation: c-Src is a component of the IKK complex. J Biochem. 2005; 137: 189-197.

25. Seong J, Lu S, Ouyang M, Huang H, Zhang J, Frame MC et al. Visualization of Src activity at different compartments of the plasma membrane by FRET imaging. Chem Biol. 2009; 16: 48-57.

26. de Diesbach M, Cominelli A, N'Kuli F, Tyteca D, Courtoy P. Acute ligand- independent Src activation mimics low EGFinduced EGFR surface signalling and redistribution into recycling endosomes. Exp Cell Res. 2010; 316: 3239-3253.

27. Ligtenberg M, Buijs F, Vos H, Hilkens J. Suppression of cellular aggregation by high levels of episialin. Cancer Res. 1992; 52: 223-232.

28. Wesseling J, van der Valk S, Vos H, Sonnenberg A, Hilkens J. Episialin (MUC1) overexpression inhibits integrin-mediated cell adhesion to extracellular matrix components. J Cell Biol. 1995; 129: 255-265.

29. Shen Q, Rahn J, Zhang J, Gunasekera N, Sun X, Bernier A et al. MUC1 initiates Src.CrkL-Rac1/Cdc42-mediated actin cytoskeletal protrusive motility after ligating intercellular adhesion molecule-1. Mol Cancer Res. 2008; 6: 555-567.
30. Friedl P, Alexander S. Cancer invasion and the microenvironment: plasticity and reciprocity. Cell. 2011; 147: 992-909.

31. De La Torre A, Carrillo LM, Rojas H, Ramírez R, Reyes $O$, Arciniegas E. La hiperplasia epidérmica observada en carcinoma basocelular podría involucrar la migración e invasión colectiva de los queratinocitos: posible papel del receptor CD44 y la tirosina quinasa c-Src en su forma activada. Dermatol Venez. 2012; 50: 19-29.

32. Carson DD. The cytoplasmic tail of MUC1: A very busy place. Sci Signal. 2008; 1 (27): pe35.

33. Dong W, Li Y, Gao M, Hu M, Li X, Mai S et al. IKK $\alpha$ contributes to UVB-induced VEGF expression by regulating AP-1 transactivation. Nucleic Acids Res. 2012; 40: 2940-2955.

34. Huang WC, Hung MC. Beyond NF-KB activation: nuclear functions of IкB kinase $\alpha$. J Biomed Sci. 2013; 20: 1-13.

35. Na S, Collin O, Chowdhury F, Tay B, Ouyang M, Wang Y et al. Rapid signal transduction in living cells is a unique feature of mechanotransduction. Proc Natl Acad Sci. USA. 2008; 105: 6626-6631.

36. Honore S, Pasquier E, Braguer D. Understanding microtubule dynamics for improved cancer therapy. Cell Mol Life Sci. 2005; 62: 3039-3056.

37. Wang $Y$, Yamaguchi $H$, Hsu J, Hung M. Nuclear trafficking of the epidermal growth factor receptor family membrane proteins. Oncogene. 2010; 29: 3997-4006. 